\title{
Evaluation of Factors Affecting Wrist Radio-Cephalic Arteriovenous Fistula Maturation: A Single Institutional Observational Study
}

\author{
Vikram Prabha ${ }^{1}$, Ritesh R. Vernekar ${ }^{2,}{ }^{*}$, Priyeshkumar Patel ${ }^{1}$, Shridhar C. Ghagane ${ }^{3}$ and Rajendra B. \\ Nerli $^{1}$ \\ ${ }^{1}$ Department of Urology, JN Medical College, KLE Academy of Higher Education and Research (Deemed-to-be-University), JNMC Campus, Nehru Nagar, Belagavi-590010, \\ Karnataka, India \\ ${ }^{2}$ Department of Nephrology, JN Medical College, KLE Academy of Higher Education and Research (Deemed-to-be-University), JNMC Campus, Nehru Nagar, Belagavi-590010, \\ Karnataka, India. \\ ${ }^{3}$ KLE Academy of Higher Education and Research (Deemed-to-be-University), JNMC Campus, Nehru Nagar, Belagavi-590010, Karnataka, India \\ "Corresponding author: Department of Nephrology, JN Medical College, KLE Academy of Higher Education and Research (Deemed-to-be-University), JNMC Campus, Nehru \\ Nagar, Belagavi-590010, Karnataka, India. Email: riteshvernekar@gmail.com
}

Received 2021 August 23; Accepted 2021 September 26.

\begin{abstract}
Background: Chronic renal failure is the most common indication for which arterio-venous (AV) fistula creation surgery is being performed. Various studies have found that native arteriovenous fistulas are the best in long-term patency with lower complications. We conducted this study to find out the role of preprocedural duplex ultrasound (DUS) in predicting outcomes of radiocephalic fistula in the wrist in the North-Karnataka population.

Methods: This prospective study was conducted from May 2019 to July 2020 on 50 patients who were hemodialysis-dependent and underwent AV fistula creation with age from 20 to 70 years. All the patients underwent preoperative DUS and were followed up post-operatively after one, two, and six weeks. Hemodialysis was initiated through the constructed fistula once it was mature, and the maximum blood flow through the fistula was measured. SPSS version 20.0 was used for statistical analysis.

Results: Among 50 subjects, the overall cumulative success of AVF maturation was 86\% (43), and failure to mature rate was 14\% (7). Logistic regression of maturation outcome in the wrist autologous arteriovenous fistula for individual factors showed statistically significant results $(\mathrm{P}<0.05)$ for the diameter of the radial artery $>1.6 \mathrm{~mm}$ and the distensibility of the cephalic vein $>0.4 \mathrm{~mm}$. Conclusions: Vein distensibility and radial artery diameter are key factors in predicting successful AVF maturation. The use of intraoperative papaverine instillation directly on vessels can improve arteriovenous fistula outcomes.
\end{abstract}

Keywords: End Stage Renal Disease, Duplex Ultrasound, Hemodialysis

\section{Background}

The preferred modality for hemodialysis access is the native arteriovenous fistula (AVF), although the high incidence of fistulas that do not mature is a major obstacle to increased use. When compared to grafts, it has a low complications rate and requires few secondary procedures compared to grafts. It is also associated with longer usability and functional patency rates (1). The kidney disease outcome initiative (KDOQI) recommends wrist RCAVF as the initial and better site for AVF construction (2). Though it has some advantages like preservation of proximal vessels and ease of performing, wrist RCAVF has a few drawbacks like a high failure rate (3). The blood flow through the fistula and its patency over a period of time are key factors for successful outcome. Preoperative vessel assessment with B-mode ultrasonography (USG) and color doppler im- proves the success of creation and outcome of native AVF (4).

Several studies have analyzed factors responsible for failure, such as increasing age, female gender, race, and comorbid conditions like diabetes, cerebrovascular diseases, or peripheral vascular diseases (5-7). Despite multiple studies conducted by various authors to analyze preoperative variables identified using duplex ultrasound in predicting successful functional maturation of RCAVF, the optimal vessel size is a main question for successful AVF creation. There is great variation in predictive values for AVF failure $(8,9)$ as suggested by different authors. The period of maturation is the time from AVF creation to the first successful cannulation. This study was performed to find out the role of preprocedural DUS in the prediction of RCAVF functional maturation in the wrist and to identify the modifiable factors in the technique of surgery for improving 
RCAVF success.

\section{Methods}

This study included 50 consecutive patients with end-stage kidney disease (ESRD), who underwent RCAVF surgery between May 2019 and April 2020. All the patients were hospitalized in the KLES Dr. Prabhakar Kore Hospital to create a primary native radio-cephalic AVF.

\subsection{Inclusion Criteria}

All patients aged 20 to 70 years diagnosed with ESRD who are hemodialysis dependent and undergo AV fistula creation in the non-dominant upper limb.

\subsection{Exclusion Criteria}

- Age $<20$ years or $>70$ years,

- Patients with thrombosed upper limb veins,

- ESRD patients requiring prosthetic graft, and

- Multiple pricks in the non-dominant upper limb for venous access.

Written informed consent was obtained from each patient. Ethical clearance was obtained from the institutional Ethics Committee. Data was collected regarding baseline demographic information.

All the patients were examined according to a standard color doppler protocol. An ultrasound was performed using a BK medical (Profocus) ultrasound machine with 7$10 \mathrm{MHz}$ frequency linear probe. A practitioner who was trained by a radiologist performed the duplex ultrasound (DUS), and some variables were cross-checked by another ultra-sonographer randomly for ensuring the standardization of the technique.

All the patients underwent the preoperative DUS assessment of the non-dominant upper limb vessels. Cephalic vein diameter(CVd), radial-artery diameter(RAd), and peak systolic velocity (PSV RA) were measured near the wrist. The blood vessels were calipered, and their distensibility was measured using the B mode. Vein diameter before tourniquet was measured as (VDo), and after the application of a tourniquet for 2 minutes at $90 \mathrm{mmHg}$ pressure at elbow, it was measured as VD1. Vein distensibility (VD) was calculated as: [VD $(\mathrm{mm})=$ VD1-VDo]. Cephalic vein compressibility was assessed, and patients with noncompressible cephalic vein (thrombosed) were excluded from the study. Peak systolic velocity of the radial artery (PSV RA) was measured over the radial artery in the longitudinal plane, and the angle was kept below $60^{\circ}$ (10-12).

In all the patients, RCAVFs were created at a level just proximal to the wrist. All surgeries were done by three trained surgeons (a senior urologist or a senior registrar under supervision). Preoperative vascular mapping was done for each patient to help in identifying smaller tributaries at distance of $5-10 \mathrm{~cm}$ from the AVF creation site. (Figure 1A) All surgeries were performed under local anesthesia. We performed an approximately 8-mm arteriotomy and a 10-mm venotomy (unstretched venous length). (Figure $1 \mathrm{~B}$ ) Veins were flushed with heparinized saline. CV to RA end-to-side anastomoses were done with running 6'0' polypropylene. (Figure 1C) Immediately after anastomosis, we instilled $1 \mathrm{cc}$ papaverine around the anastomosis and along the outflow vein in all the patients.

All the patients underwent preoperative duplex ultrasound examination and were followed up post-operatively after one, two, and six weeks. Hemodialysis was initiated through the constructed fistula once it was mature, and the maximum blood flow through the fistula was measured. SPSS version 20.0 was used for statistical analysis.

Patients in whom dilatation was not adequate were reassessed after two weeks.

\subsection{Criteria for Successful Maturation}

- Ease of puncture,

- Successful HD for more than four hours through fistula for three or more consecutive HD sessions, and

- Fistula providing blood flow of $250 \mathrm{ml} / \mathrm{min}$ or more for four hours.

Any AVF thrombosed immediately or any time after construction or failed to meet the above-mentioned criteria was considered failed fistula.

\subsection{Statistical Analysis}

All the data were entered in a predesigned pro forma. Patient information such as age, gender, and associated comorbidities, such as diabetes, hypertension, cerebrovascular diseases, or peripheral vascular diseases, were recorded. All DUS findings as described earlier were entered into the data. SPSS v 20.0 was used for statistical analysis. Means of DUS variables between subjects with successful and failed maturation as well as diabetics and non-diabetics with maturation failure were compared with independent $t$-test. Outcomes were compared using Chi-square test and Fisher's exact test. The cut-off point of 0.05 was considered statistically significant. Multiple variable logistic regression analysis was used to find out the factors associated with the specific predetermined AVF outcome, that is, absolute success (AS) vs. relative failure (RF). The multivariable equation was used to estimate the probability of successful outcome of AVF. 

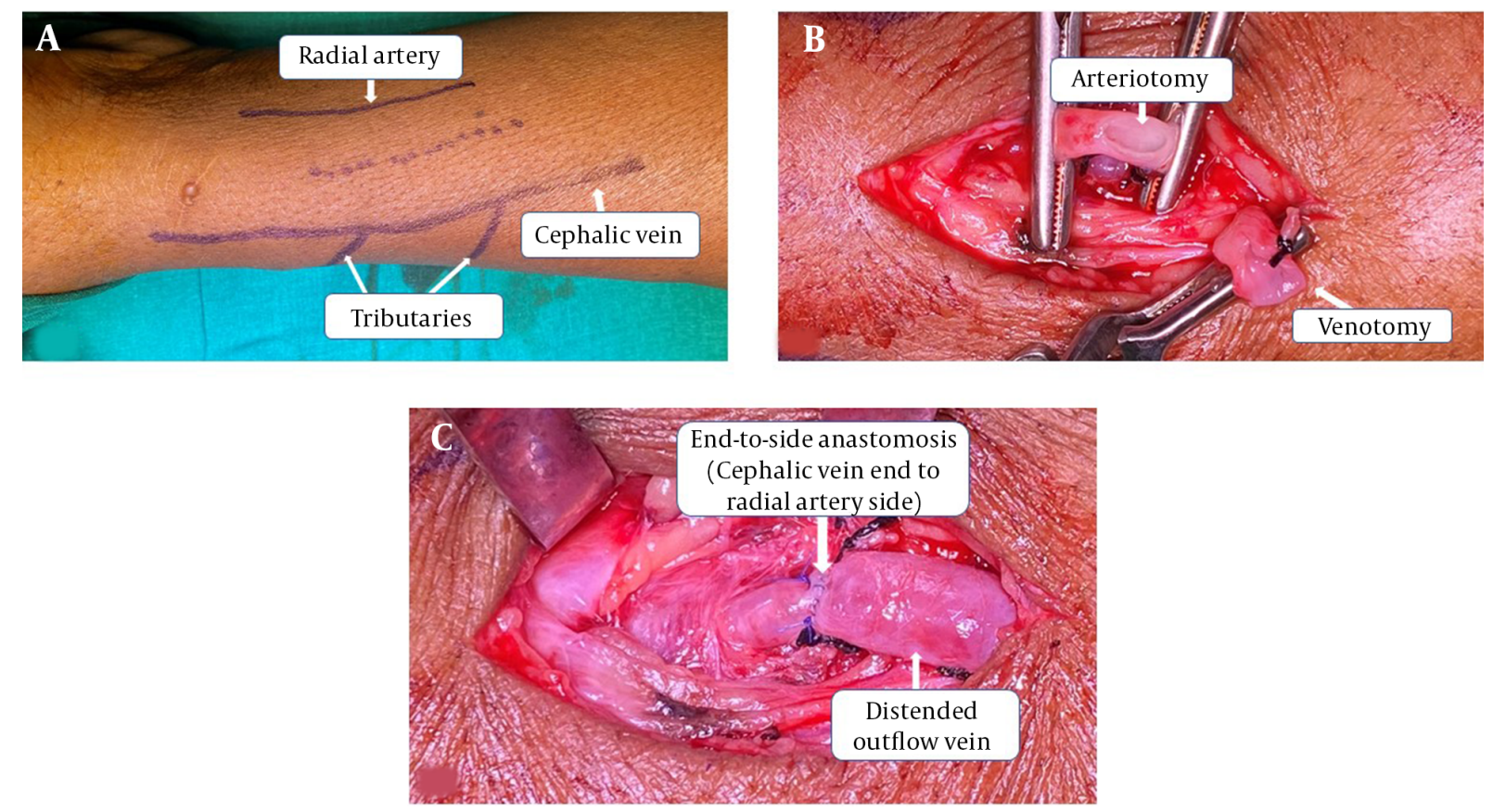

Figure 1. (A) Vascular marking with the guidance of duplex ultrasound gray scale. (B) Intra-operative picture showing arteriotomy and venotomy after applying vascular clamps. (C) Cephalic vein end-to-radial artery side anastomosis completed with distended outflow vein after clamp release

\section{Results}

Overall, 50 patients were included in the study. Baseline patient data is shown in Table 1. The mean age was $52.22 \pm 14.04$ years (range, 20 to 70 years). Duplex ultrasound findings of various morphologic and functional parameters are presented in Table 2. Successful RCAVF maturation was noted in $86 \%$ (43). This included $78 \%$ with successful RCAVF maturation in four weeks (39) and $22 \%$ with prolonged maturation during six to eight weeks (4). Failure to mature rate was $14 \%$ (7).

\begin{tabular}{lc}
\hline Table 1. Baseline Characteristics & \\
\hline Variables & No. (\%) \\
\hline Total number of patients & $50(100)$ \\
\hline Male & $43(86)$ \\
\hline Female & $7(14)$ \\
\hline Age $>$ 55 years & $24(48)$ \\
\hline Diabetes & $11(22)$ \\
\hline Hypertension & $41(82)$ \\
\hline Non-Dominant Upper limb: Left & $46(92)$ \\
\hline Non-Dominant Upper limb: Right & $4(8)$ \\
\hline
\end{tabular}

We found a statistically significant correlation between outcome of RCAVF and RAd, PSV RA, VD. However, we did not find a significant correlation between RCAVF outcome and CVD. The analyzed results of absolute success to absolute failure ratio are shown in Table 3. We found threshold of RAd $>1.6 \mathrm{~mm}$ as a predictive variable for the relative success vs. relative failure of $\mathrm{AVF}$ at $95 \% \mathrm{CI}$ (1.39 to 35.98) with a P-value of 0.01. We also found the threshold of PSV RA $>25 \mathrm{~cm} / \mathrm{s}$ as a predictive variable for the relative success vs. relative failure of AVF at $95 \% \mathrm{CI}(2.49-90.23)$ with a P-value of 0.003. This result was also associated with highest odds ratio 15:1 (Odds of success). The value of VD $>0.4 \mathrm{~mm}$ for success vs. failure outcome was also statistically significant with a P-value of 0.04 at $95 \% \mathrm{CI}(1.07$ to 33.64). The value of CVD $>2 \mathrm{~mm}$ was not statistically significant for the correlation of successful AVF outcome with the relative failure of AVF outcome. Based on the analysis obtained ( $\mathrm{CI} 0.16$ to $3.41, \mathrm{P}=0.70$ ), prolonged maturation or failure to mature rate was higher in females. $(\mathrm{OR}=6 ; 95 \%$ $\mathrm{CI}=1.17-30.72 ; \mathrm{P}=0.03$ ) The arterial and venous diameters were lower in women than in men, although there were no statistically significant differences between them.

\section{Discussion}

Maturation criteria are not well defined, and there is a great variability in data around the world. Data from the DOPPS study revealed that AVF puncture was done in the 
Prabha Vetal.

\begin{tabular}{|c|c|c|c|c|}
\hline & RAd & PSV RA & CVd & VD \\
\hline \multicolumn{5}{|l|}{ All } \\
\hline Mean & 2.18 & 33.57 & 2.04 & 0.84 \\
\hline Minimum & 1.4 & 24.8 & 1.2 & 0.08 \\
\hline Maximum & 3.12 & 55.8 & 4.11 & 2.03 \\
\hline SD & 0.36 & 10.28 & 0.57 & 0.42 \\
\hline \multicolumn{5}{|l|}{ Male } \\
\hline Mean & 2.21 & 34.03 & 2.06 & 0.85 \\
\hline Minimum & 1.4 & 12 & 1.2 & 0.08 \\
\hline Maximum & 2.4 & 39 & 4.11 & 2.03 \\
\hline SD & 0.38 & 10.66 & 0.60 & 0.43 \\
\hline \multicolumn{5}{|l|}{ Female } \\
\hline Mean & 2.03 & 30.84 & 1.91 & 0.80 \\
\hline Minimum & 1.5 & 20 & 1.46 & 0.6 \\
\hline Maximum & 2.27 & 42.1 & 2.41 & 1.15 \\
\hline SD & 0.26 & 7.75 & 0.38 & 0.43 \\
\hline
\end{tabular}

Table 3. Logistic Regression of Maturation Outcome (Success vs Failure) in Wrist RCAVF

\begin{tabular}{lcc}
\hline Independent Variable & OR (CI 95\%) & P Value \\
\hline Sex F/M & $6.0000(1.1717$ to 30.7255$)$ & 0.03 \\
\hline Age $<\mathbf{5 5}$ vs $>\mathbf{5 5}$ & $1.1000(0.2424$ to 4.9916$)$ & 0.90 \\
\hline RAd $>\mathbf{1 . 6}$ vs $<\mathbf{1 . 6} \mathbf{~ m m}$ & $7.0833(1.3942$ to 35.9878$)$ & 0.001 \\
\hline PSV RA & $15.0000(2.4936$ to 90.2318$)$ & 0.003 \\
\hline CVd $>\mathbf{1 . 8}$ vs. $<\mathbf{1 . 8}$ & $0.7500(0.1649$ to 3.4110$)$ & 0.709 \\
VD $>$ 0.4 vs. $<\mathbf{0 . 4}$ & $6.0000(1.0700$ to 33.6463$)$ & 0.004 \\
\hline
\end{tabular}

first month of construction in 74\% of HD centers in Japan, $50 \%$ in Europe, and $<2 \%$ in the US (13). Saran et al. noted that poor outcome was not related to AVF puncture within one month, and AVF should be cannulated after four weeks $(13,14)$. They also suggested that decision about AVF suitability for cannulation should be based on clinical examination and objective measurement techniques, such as color doppler ultrasound (14).

Malovrh reported $80.2 \%$ of distal AVF successfully mature after twelve weeks (9), while other authors reported different failure-to-mature rates and recommended different maturation periods $(6,7,15,16)$. In most HD centers, blood flow of $250-350 \mathrm{~mL} / \mathrm{min}$ for 4 hours HD session is a routine practice. Routinely they waited for four weeks prior to initial cannulation, but we waited for more the 6 weeks for some patients. Most of them requires addition intervention if they do not mature within 8 weeks.
In our study, at 4 weeks, $78 \%$ of the patients meet maturation criteria, and delayed maturation was noted in $22 \%$ of patients, who attained functional maturation after eight weeks. The overall cumulative successful maturation rate was $84 \%$. Our results are slightly higher than several other studies $(9,17)$.

In our study, 7 fistulas failed to mature, out of which 3 patients had events of hypotension during dialysis through another access, 2 patients had thrombus at AVF site, 1 patient had stenosis in the outflow vein, and 1 was failed immediately after surgery.

The impact of gender on the outcome of AVF is currently the subject of many studies. Some authors concluded that female gender is an independent risk factor for a positive outcome of $\operatorname{AVF}(2,15,18)$. Our study also found that female gender has higher rates of failure than male gender $(\mathrm{P}=0.03)$. There is a great variation in defining the minimum RAd for successful outcome of wrist. Like, some authors recommend a diameter of $1.5 \mathrm{~mm}(9,10)$, others 1.6 $\mathrm{mm}$ (11), whereas other authors suggest the limit of $>2.1$ $\mathrm{mm}$ (12). However, the size of the feeding artery supplying blood to the AVF definitely contributes to a favorable outcome. Silva et al. reported only $8.3 \%$ of primary AVF failure when RAd and CVd of $>2 \mathrm{~mm}$ and $>2.5 \mathrm{~mm}$ taken as criteria (8). Whilst Lockhart et al. obtained a significantly lower rate of successful AVF -36\% with the same criteria (19). In our study RAd > $1.6 \mathrm{~mm}$ showed better success rate, which was statistically significant ( $95 \%$ CI 1.39 to $35.98, \mathrm{P}=0.01$ ).

For vein diameter, some authors found out higher AVF 
success rates in patients with $>2 \mathrm{~mm}$ veins (20), while others reported a marginal diameter of $2.6 \mathrm{~mm}$, but only in women (21). Though the vein's internal diameter is not always taken as an influencing factor for the outcome of AVF, some authors concluded all AVFs with the vein diameters $<$ $1.6 \mathrm{~mm}$ were unsuccessful (11). The results of our study did not confirm the effect of CVd on AVF outcomes.

These differences suggest that vascular diameter is a critical but not the sole determinant for AVF maturation, which points towards other significant factors like blood vessels' functional characteristics that might be affecting AVF maturation (9). In addition, vein distensibility (VD) is also an important parameter for predicting AVF outcome $(9,22,23)$. After anastomosing the vein to an artery, it leads to increased blood flow, causing subsequent dilatation. The dilatation of the vein depends on wall characteristics, which can be affected by several factors like inflammation or previous punctures in the wall. Various methods have been evaluated for vein distensibility test like warm water (24), compression over the proximal vein (6), and supine position (25). Kim et al. evaluated change in vein diameter after tourniquet application and found that there was a 7.4 times higher chance of successful AVF maturation when diameter increased by $>0.35 \mathrm{~mm}$ (23). The results of our study indicated that VD $>0.4 \mathrm{~mm}$ is an important factor for the prediction of successful AVF maturation $(\mathrm{P}=$ 0.001).

Patients with VD $>0.4 \mathrm{~mm}$ had a six-fold higher likelihood of a successful outcome (OR of 6.00, P = 0.001). Our results are consistent with earlier findings suggesting that VD is a significant factor affecting the outcome of AVF $(4,9,22)$. In our study, VD was expressed in millimeters, whereas other authors expressed VD as a percentage (9) or as $\mathrm{mL} / \mathrm{mmHg}(26)$.

Our method of accessing venous distensibility also differs from that of Kim et al. (23). It can be used in small centers as it is easily feasible, easily reproducible, and does not require additional apparatus or contrast exposure.

The majority of AV fistula fail due to low flow through the fistula, which may contribute in thrombus formation in the presence of an intimal injury. Low fistula blood flow due to arterial spasm and venous spasm around the edge of dissection is thought to be the main cause of low flow through AVF. In this situation, increased transit time in the presence of an intimal injury may easily evoke thrombosis of the anastomosis. By applying local anesthetics, we can achieve venous dilatation, whereas papaverine hydrochloride has a rapid effect on both the artery and vein, which in turn helps in preventing thrombus formation. A few studies in the literature have shown the use of papaverine for successful AVF outcomes $(27,28)$. We did not use LMWH for any patients included in our study, which helped in reducing the overall cost. Using papaverine, we can eliminate the need for LMHW with almost similar or better outcomes. Nonetheless, it is difficult to conclude based on our study as there was no control group in our study and our study population was small $(n=50)$. Furthermore, we evaluated only immediate outcomes and not the long-term survival of AVF. Thus, further randomized studies with longer follow-ups are warranted to define the exact role of papaverine in successful outcomes of AV fistula.

\subsection{Conclusion}

In sum, vein distensibility $(>0.4 \mathrm{~mm})$ and radial artery diameter $(>1.6 \mathrm{~mm})$ are key factors in predicting successful AVF maturation. Most RCAVFs meet maturation criteria after four weeks and some after eight weeks. Female gender has a high failure rate as compared to male gender. In our study, the rate of functional maturation was higher than in other studies, which could be due to the intraoperative use of papaverine (vasodilatory effect helping in early maturation). As papaverine has a safe pharmacologic profile, it is safe to use locally. Considering its safety profile in addition to low cost and ease of application, it can be considered a potential drug for the improved maturation rate of AVF surgery. However, further studies with larger sample sizes are needed to evaluate the effects of local papaverine on AVF maturation in ESRD patients.

\section{Footnotes}

Authors' Contribution: Vikram Prabha: Developed the study concept and design, did the analysis and interpretation of data, wrote the manuscript, reviewed and edited. Ritesh R. Vernekar: Did critical revision of the manuscript for important intellectual content, supervised the study, did the correspondence, reviewed and approved the manuscript. Priyeshkumar Patel: Did the data acquisition, administrative, technical, material suppot, reviewed and approved the manuscript. Shridhar C. Ghagane: Did the statistical analysis, reviewed the manuscript and approved. Rajendra B. Nerli: Gave the technical support, reviewed the manuscript, and approved.

Conflict of Interests: The authors declare that they have no conflicts of interest.

Data Reproducibility: The data presented in this study are openly available in one of the repositories or will be available on request from the corresponding author by this journal representative at any time during submission or after publication. Otherwise, all consequences of possible withdrawal or future retraction will be with the corresponding author. 
Ethical Approval: The study was approved by the Institutional/University Ethics Committee. IRC approval number: MDC/DOME/118.

Funding/Support: No Financial support was taken from any funding agency.

Informed Consent: Written informed consent was obtained from each patient.

\section{References}

1. Konner K, Nonnast-Daniel B, Ritz E. The arteriovenous fistula. J Am Soc Nephrol. 2003;14(6):1669-80. doi: 10.1097/01.asn.0000069219.88168.39. [PubMed: 12761270].

2. No authors listed. Clinical practice recommendations for peritoneal dialysis adequacy. Am J Kidney Dis. 2006;48 Suppl 1:S130-58. doi: 10.1053/j.ajkd.2006.04.013. [PubMed: 16813985].

3. Tordoir J, Canaud B, Haage P, Konner K, Basci A, Fouque D, et al. EBPG on Vascular Access. Nephrol Dial Transplant. 2007;22 Suppl 2:ii88-117. doi: 10.1093/ndt/gfm021. [PubMed: 17507428].

4. Ferring M, Henderson J, Wilmink A, Smith S. Vascular ultrasound for the pre-operative evaluation prior to arteriovenous fistula formation for haemodialysis: review of the evidence. Nephrol Dial Transplant. 2008;23(6):1809-15. doi: 10.1093/ndt/gfn001. [PubMed: 18326561].

5. Miller PE, Tolwani A, Luscy CP, Deierhoi MH, Bailey R, Redden DT, et al. Predictors of adequacy of arteriovenous fistulas in hemodialysis patients. Kidney Int. 1999;56(1):275-80. doi: 10.1046/j.15231755.1999.00515.x. [PubMed: 10411703].

6. Feldman HI, Joffe M, Rosas SE, Burns JE, Knauss J, Brayman K. Predictors of successful arteriovenous fistula maturation. Am J Kidney Dis. 2003;42(5):1000-12. doi: 10.1016/j.ajkd.2003.07.003. [PubMed: 14582044].

7. Lok CE, Allon M, Moist L, Oliver MJ, Shah H, Zimmerman D. Risk equation determining unsuccessful cannulation events and failure to maturation in arteriovenous fistulas (REDUCE FTM I). J Am Soc Nephrol. 2006;17(11):3204-12. doi: 10.1681/ASN.2006030190. [PubMed: 16988062].

8. Silva JMB, Hobson Ii RW, Pappas PJ, Jamil Z, Araki CT, Goldberg MC, et al. A strategy for increasing use of autogenous hemodialysis access procedures: Impact of preoperative noninvasive evaluation. J Vasc Surg. 1998;27(2):302-8. doi: 10.1016/s0741-5214(98)70360-x.

9. Malovrh M. Native arteriovenous fistula: preoperative evaluation. Am J Kidney Dis. 2002;39(6):1218-25. doi: 10.1053/ajkd.2002.33394. [PubMed: 12046034].

10. Parmar J, Aslam M, Standfield N. Pre-operative radial arterial diameter predicts early failure of arteriovenous fistula (AVF) for haemodialysis. Eur J Vasc Endovasc Surg. 2007;33(1):113-5. doi: 10.1016/j.ejvs.2006.09.001. [PubMed: 17030130].

11. Wong V, Ward R, Taylor J, Selvakumar S, How TV, Bakran A. Factors associated with early failure of arteriovenous fistulae for haemodialysis access. European Journal of Vascular and Endovascular Surgery. 1996;12(2):207-13. doi: 10.1016/s1078-5884(96)80108-0.

12. Korten E, Toonder IM, Schrama YC, Hop WC, van der Ham AC, Wittens $\mathrm{CH}$. Dialysis fistulae patency and preoperative diameter ultrasound measurements. Eur JVasc Endovasc Surg. 2007;33(4):467-71. doi: 10.1016/j.ejvs.2006.10.035. [PubMed: 17196852].

13. Saran R, Dykstra DM, Pisoni RL, Akiba T, Akizawa T, Canaud B, et al. Timing of first cannulation and vascular access failure in haemodialysis: an analysis of practice patterns at dialysis facilities in the DOPPS.
Nephrol Dial Transplant. 2004;19(9):2334-40. doi: 10.1093/ndt/gfh363. [PubMed: 15252160].

14. Saran R, Pisoni RL, Young EW. Timing of first cannulation of arteriovenous fistula: are we waiting too long? Nephrol Dial Transplant. 2005;20(4):688-90. doi: 10.1093/ndt/gfh730. [PubMed: 15772263].

15. Robbin ML, Chamberlain NE, Lockhart ME, Gallichio MH, Young $\mathrm{CJ}$, Deierhoi MH, et al. Hemodialysis arteriovenous fistula maturity: US evaluation. Radiology. 2002;225(1):59-64. doi: 10.1148/radiol.2251011367. [PubMed: 12354984].

16. Peterson WJ, Barker J, Allon M. Disparities in fistula maturation persist despite preoperative vascular mapping. Clin J Am Soc Nephrol. 2008;3(2):437-41. doi: 10.2215/CJN.03480807. [PubMed: 18235150]. [PubMed Central: PMC2390953].

17. Brescia MJ, Cimino JE, Appel K, Hurwich BJ. Chronic hemodialysis using venipuncture and a surgically created arteriovenous fistula. $N$ Engl J Med. 1966;275(20):1089-92. doi: 10.1056/NEJM196611172752002. [PubMed: 5923023].

18. Allon M, Lockhart ME, Lilly RZ, Gallichio MH, Young CJ, Barker J, et al. Effect of preoperative sonographic mapping on vascular access outcomes in hemodialysis patients. Kidney Int. 2001;60(5):2013-20. doi: 10.1046/j.1523-1755.2001.00031.x. [PubMed: 11703621].

19. Lockhart ME, Robbin ML, Allon M. Preoperative sonographic radial artery evaluation and correlation with subsequent radiocephalic fistula outcome. J Ultrasound Med. 2004;23(2):161-8. quiz 169-71. doi: 10.7863/jum.2004.23.2.161. [PubMed: 14992353].

20. Mendes RR, Farber MA, Marston WA, Dinwiddie LC, Keagy BA, Burnham SJ. Prediction of wrist arteriovenous fistula maturation with preoperative vein mapping with ultrasonography. J Vasc Surg. 2002;36(3):460-3. doi: 10.1067/mva.2002.126544. [PubMed: 12218967].

21. Brimble KS, Rabbat Ch G, Treleaven DJ, Ingram AJ. Utility of ultrasonographic venous assessment prior to forearm arteriovenous fistula creation. Clin Nephrol. 2002;58(2):122-7. doi: 10.5414/cnp58122. [PubMed: 12227684].

22. van der Linden J, Lameris TW, van den Meiracker AH, de Smet AA, Blankestijn PJ, van den Dorpel MA. Forearm venous distensibility predicts successful arteriovenous fistula. Am J Kidney Dis. 2006;47(6):10139. doi: 10.1053/j.ajkd.2006.01.033. [PubMed: 16731296].

23. Kim JT, Chang WH, Oh TY, Jeong YK. Venous distensibility as a key factor in the success of arteriovenous fistulas at the wrist. Ann Vasc Surg. 2011;25(8):1094-8. doi: 10.1016/j.avsg.2011.05.014. [PubMed: 21705188].

24. van Bemmelen PS, Kelly P, Blebea J. Improvement in the visualization of superficial arm veins being evaluated for access and bypass. JVasc Surg. 2005;42(5):957-62. doi: 10.1016/j.jvs.2005.06.021. [PubMed: 16275454].

25. Tordoir JH, Mickley V. European guidelines for vascular access: clinical algorithms on vascular access for haemodialysis. EDTNA ERCA J. 2003;29(3):131-6. doi: 10.1111/j.1755-6686.2003.tb00293.x. [PubMed: 14552086].

26. Wall LP, Gasparis A, Callahan S, van Bemmelen P, Criado E, Ricotta J. Impaired hyperemic response is predictive of early access failure. Ann Vasc Surg. 2004;18(2):167-71. doi: 10.1007/s10016-004-0006-9. [PubMed: 15253251].

27. Iyem H. Early follow-up results of arteriovenous fistulae created for hemodialysis. Vasc Health Risk Manag. 2011;7:321-5. doi: 10.2147/VHRM.S14277. [PubMed: 21633522]. [PubMed Central: PMC3104609].

28. Kazemzadeh G, Saberi A, Manani R, Sadeghipour F, Rahmani A. Effect of local papaverine on arteriovenous fistula maturation in patients with end-stage renal disease.J Bras Nefrol.2019;41(2):185-92. doi: 10.1590/2175-8239-JBN-2018-0170. [PubMed: 31498862]. [PubMed Central: PMC6699447]. 